\title{
Avaliação de diferentes materiais para recobrimento de camas em baias de galpão modelo free-stall
}

\author{
Daiane Cecchin ${ }^{1}$, Alessandro T. Campos ${ }^{2}$, Maria de F. A. Pires ${ }^{3}$, Renato R. de Lima ${ }^{4}$, \\ Tadayuki Yanagi Junior ${ }^{5} \&$ Myriam C. M. Souza
}

\author{
${ }^{1}$ DEG/UFLA, Lavras, MG. E-mail: daianececchin@yahoo.com.br (Autor correspondente) \\ ${ }^{2}$ DEG/UFLA, Lavras, MG. E-mail: campos@deg.ufla.br \\ ${ }^{3}$ Embrapa Gado de Leite, Juiz de Fora, MG. E-mail: fatinha@cnpgl.embrapa.br \\ ${ }^{4}$ DEX/UFLA, Lavras, MG. E-mail: rrlima@dex.ufla.br \\ ${ }^{5}$ DEG/UFLA, Lavras, MG. E-mail: yanagi@deg.ufla.br \\ ${ }^{6}$ UNIPAC, Juiz de Fora, MG. E-mail: myriammorais@hotmail.com
}

\section{Palavras-chave:}

comportamento

conforto

gado de leite

confinamento

construções rurais

\begin{abstract}
R E S U M O
Objetivou-se, com o presente trabalho, comparar o uso de cama de colchão de borracha e de areia no recobrimento da superfície de baias para confinamento tipo free-stall. Foram monitoradas 18 vacas holandesas confinadas em galpão modelo free-stall cujas baias foram recobertas com camas de areia e colchão de borracha (tratamentos). O delineamento experimental foi em blocos casualizados. Os parâmetros comportamentais estudados foram os tempos despendidos nas atividades: deitada em ócio e deitada ruminando, em pé em ócio sobre a cama, em pé ruminando sobre a cama, registrados a cada $10 \mathrm{~min}$. As variáveis ambientais e temperatura da superfície das camas foram registradas a cada hora. Houve maior preferência dos animais pela cama de areia para os comportamentos deitada em ócio e deitada ruminando. As vacas permaneceram mais tempo deitadas em cama de borracha somente nos períodos mais frescos (noite e madrugada), devido à temperatura da cama. A temperatura da borracha foi maior que areia nos horários mais quentes do dia (notadamente durante o período da tarde), enquanto à noite se apresentou mais fria.
\end{abstract}

Key words:

behavior

comfort

dairy cattle

confinement

rural buildings

\section{Evaluation of different materials for covering beds in free-stall barn}

\begin{abstract}
A B S T R A C T
The aim of the present study was to compare the use of bed mattress, rubber and sand coating on the surface of stalls in free-stall barn. Eighteen holstein cows confined in free-stall barn were monitored whose stalls were covered with beds of sand and rubber mattress (treatments). The experimental design was randomized blocks. The studied behavioral parameters were the time spent in different activities: lying in idleness and lying ruminating, standing in idleness on the bedding, standing ruminating on the bed, recorded every $10 \mathrm{~min}$. Environmental variables and surface temperature of the bedding were recorded every hour. There was a greater preference of animals for sand bedding and the behaviors lying in idleness or lying ruminating. The cows spent more time lying on rubber bed only in cooler periods (morning and night), due to the temperature of the bedding. The temperature of the rubber was higher than sand in the hottest times of the day (especially during the afternoon), while in the evening, presented cooler.
\end{abstract}

\section{INTRODUÇÃo}

A qualidade de vida de animais confinados depende dos cuidados que lhes são atribuídos (Camerini \& Nascimento, 2012) e do ambiente onde são alojados. Este ambiente exerce influência direta sobre seu desempenho, interferindo positiva ou negativamente, dependendo do nível de conforto ou de estresse promovido por ele (Silva, 2000).

O estresse está ligado a qualquer fator que cause tensão fisiológica ou psicológica ao indivíduo (Haussmann et al., 2007). A falta do bem-estar pode ocasionar perdas econômicas consideráveis nas cadeias produtivas (Souza et al., 2007).
O animal expressa o estresse através de alterações comportamentais e fisiológicas (Fisher et al., 2002). Por este fato o comportamento se constitui em instrumento importante no diagnóstico de bem-estar animal (Bond et al., 2012). Nos últimos anos a avaliação do conforto animal com métodos não invasivos vem ganhando destaque (Castro et al., 2011).

$\mathrm{O}$ confinamento de animais surgiu como alternativa para o aumento da produtividade e com ele novas oportunidades para manejar rebanhos leiteiros com maior conforto mas como consequências surgiram novos problemas (Perissinotto et al., 2009). O material a ser utilizado como cama para os animais pode ser considerado um desses problemas quando não é adequado. 
Segundo Mitev et al. (2012), a cama deve ser confortável o suficiente para garantir um descanso e bem-estar adequados aos animais. As camas de areia são consideradas higiênicas (Zdanowicz et al., 2004) econômicas e confortáveis (Cook, 2003). Baias com colchões de borracha são consideradas mais macias (Herlin, 1997).

Mitev et al. (2012) alegam que o material de cama determina grande influência sobre o tempo que o animal permanece deitado. Fregonesi et al. (2007) complementam que o teor de umidade na cama está relacionado com a permanência dos animais em descanso nas baias.

Vacas leiteiras passam quase a metade de sua vida deitadas, em média de 12 a $14 \mathrm{~h} \mathrm{~d}^{-1}$. A redução no tempo de descanso dos animais pode resultar em alterações fisiológicas associadas ao estresse com consequências sobre a saúde e a produção das vacas (Boone, 2009).

Munksgaard et al. (2005) apontam que o descanso tem alta prioridade de tempo na fisiologia das vacas uma vez que estas passam mais tempo em descanso do que se alimentando. Por outro lado, a alimentação pode afetar o tempo de descanso o qual pode ser reduzido em dietas de baixo teor em concentrado (Nielsen et al., 2000).

O objetivo do presente trabalho foi comparar dois tipos de materiais (areia e borracha) utilizados como cama para baias de galpão free stall no confinamento de vacas da raça Holandesa.

\section{Material e Métodos}

O trabalho foi desenvolvido nas instalações do Sistema Intensivo de Produção de Leite (SIPL), da Embrapa Gado de Leite, situado no Município de Coronel Pacheco, Zona da Mata de Minas Gerais, localizado na latitude de $21^{\circ} 33^{\prime} 22^{\prime \prime}$ Sul e na longitude de $43^{\circ} 06^{\prime} 15^{\prime \prime}$ Oeste, com altitude de $414 \mathrm{~m}$. O clima da região, segundo a classificação de Köppen, é Cwa, ou seja, clima quente, temperado chuvoso, com estação seca no inverno e com verão quente e chuvoso.

$\mathrm{O}$ experimento foi realizado em galpão de confinamento modelo free-stall, com $37,1 \mathrm{~m}$ de comprimento, $36,0 \mathrm{~m}$ de largura, 7,0 m de altura, no centro, e 3,5 $\mathrm{m}$ de pé-direito, com capacidade para alojar 80 animais adultos divididos em quatro lotes.

O galpão apresenta as seguintes características: abertura total nos quatro lados, pilares de concreto pré-fabricado piso de concreto frisado, corredor central de alimentação medindo 4,5 $\mathrm{m}$ de largura e corredor de manejo de 4,1 $\mathrm{m}$ (de onde animais são conduzidos para a sala de ordenha).

A cobertura é feita com telhas de cimento amianto sendo a região da cumeeira descoberta visando obter ventilação por efeito termossifão. Os oitões são fechados com telhas de cimento amianto instaladas na posição vertical com o objetivo de reduzir a incidência de radiação solar direta no interior da instalação.

Foram utilizadas 20 baias individuais, divididas em dois grupos de 10 cada um; cada grupo foi recoberto com um tipo de material (areia ou colchão de borracha - Figura 1). A distribuição do tipo de cama nas baias foi feita de modo a

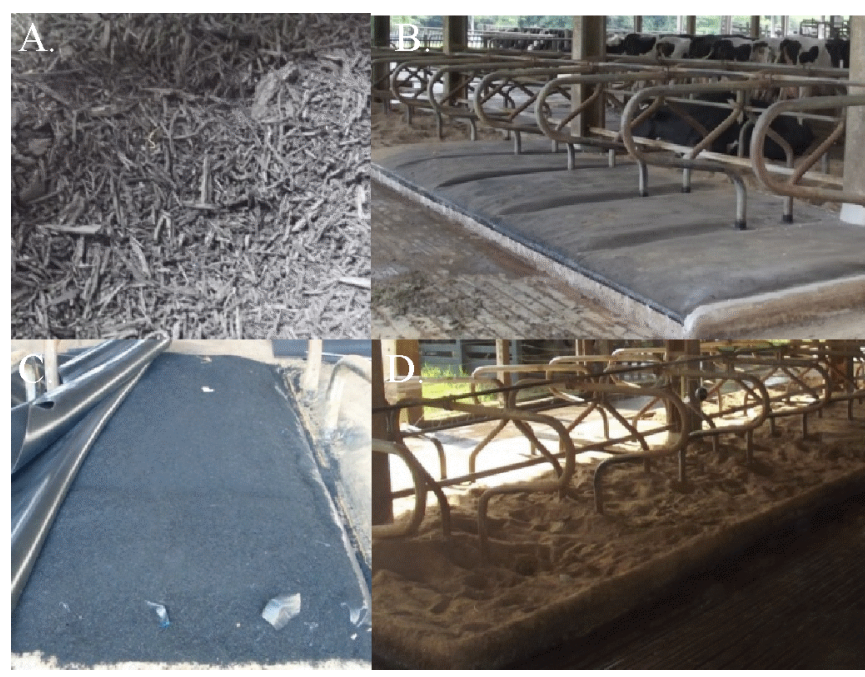

Figura 1. Borracha picada (A); camas de colchão de borracha (B); montagem da cama, com roletes recheados com borracha picada, entremeados com borracha $(C)$; camas de areia (D)

neutralizar os efeitos inerentes ao lado do galpão, ou seja, havia os dois tipos de materiais de cama (borracha e areia) em ambos os lados da ala, de forma que todas recebessem o mesmo efeito da radiação.

As vacas tinham livre acesso às baias e oportunidade de escolha de acordo com a preferência pela cama. As ordenhas eram realizadas três vezes ao dia, às $5 \mathrm{~h}$ e $30 \mathrm{~min}$, às $13 \mathrm{e}$ às $21 \mathrm{~h}$, em sala de ordenha modelo espinha de peixe, contígua ao free-stall.

Foram instalados em duas baias contíguas (um em cada lado da ala) a $70 \mathrm{~cm}$ de altura, conjuntos de termômetros de globos negros e termo-higrômetros, para determinação da temperatura de bulbo seco e úmido. Esses conjuntos também foram instalados no solário para que se pudesse comparar as variáveis ambientais interna e externamente.

A velocidade do vento foi registrada por meio de anemômetro digital, da marca Icel Manaus, modelo NA - 3090 (vazão) e precisão $\pm 3 \%$. Esses dados do ambiente térmico foram coletados de hora em hora.

Com os dados obtidos foi realizado o cálculo do Índice de Temperatura de Globo e Umidade (ITGU) através da equação proposta por Buffington et al. (1981):

$$
\mathrm{ITGU}=\mathrm{Tgn}+0,36 \mathrm{Tpo}-330,08
$$

em que:

Tgn - temperatura do globo negro, $\mathrm{K}$

Tpo - temperatura do ponto de orvalho, $\mathrm{K}$

A temperatura das camas (areia e borracha) foi determinada a cada hora, por meio de um termômetro de superficie, infravermelho, da marca Fluke modelo $62 \mathrm{Mini}$, com precisão de $\pm 1 \%$ da leitura.

Foi monitorado o comportamento de 18 vacas multíparas de raça holandesa puras de origem, com peso corporal médio de $560 \mathrm{~kg}$ e com produção média de $29,2 \mathrm{~kg} \mathrm{~d}^{-1}$. A alimentação 
volumosa era constituída de silagem de milho e $2 \mathrm{~kg}$ de capim tifton picado por animal, por dia, com o intuito de aumentar o teor de fibras da alimentação, visando reduzir a incidência de acidose nos animais.

O concentrado fornecido (13 kg por animal por dia) continha $22 \%$ de proteína bruta (PB) adicionados $100 \mathrm{~g}$ de bicarbonato de sódio. A água era disponível ad libitum. A alimentação era fornecida próximo aos seguintes horários às $7,10,14,16$ e às $21 \mathrm{~h}$.

Os regristros dos dados comportamentais e ambientais foram realizados em períodos alternados de seis horas, com a seguinte distribuição: período da manhã das 6 às 11 h e 50 min, período da tarde, das 12 às $17 \mathrm{~h}$ e 50 min, período da noite: das 18 às $23 \mathrm{~h}$ e 50 min e período da madrugada de 24 às $5 \mathrm{~h}$ e $50 \mathrm{~min}$. Foram feitas sete coletas para cada período citado perfazendo o equivalente a 7 dias.

O comportamento dos animais foi avaliado através do método de aferição visual, com observações a cada dez minutos. Em planilha foram anotados os seguintes comportamentos: deitada ruminando na cama de borracha (DRB), deitada ruminando na cama de areia (DRA), deitada em ócio na cama de borracha (DOB), deitada em ócio na cama de areia (DOB), em pé ruminando sobre a cama de borracha (ERB), em pé ócio sobre a cama de borracha (EOB), em pé ruminando sobre a cama de areia (ERA) e em pé em ócio obre a cama de areia (EOA).

A análise estatística dos dados comportamentais foi realizada em Software $S^{\circ} S^{\circ}$, por meio de delineamento em blocos casualizados, com sete repetições (dias) em um esquema fatorial $4 \times 4 \times 2$ (4 períodos: manhã, tarde, noite e madrugada x 4 atividades: DO, DR, EO, ER x 2 camas: areia e borracha), tendo-se avaliado 18 animais analisando o tempo médio das vacas em cada atividade. Para que as pressuposições da análise de variância em ambas fases fossem atendidas utilizou-se como variável resposta, a raiz quadrada do tempo e, para a análise de variância, aplicou-se o teste $\mathrm{F}$ a 0,05.

\section{Resultados e Discussão}

No período da manhã foi detectada maior preferência pelas camas de areia (Tabela 1). Provavelmente por causa da temperatura da cama influenciada, por sua vez, pela incidência de radiação. As vacas permaneceram mais tempo deitadas (no ócio e ruminando) na areia (89 min e 2 s) que no colchão de borracha (63 min e $58 \mathrm{~s}$ ); quanto à posição em pé, não houve diferença na utilização das camas.

No período da tarde, independente da posição (em pé ou deitada), as vacas ficaram mais tempo na cama de areia enquanto à noite esta preferência foi observada apenas enquanto estavam deitadas ruminando ( $33 \mathrm{~min}$ e $58 \mathrm{~s}$ na areia e $18 \mathrm{~min}$ e $5 \mathrm{~s}$ na borracha, respectivamente) (Tabela 1 ).

Durante a madrugada, período no qual os animais se encontravam mais cansados, e percebendo condições de temperatura semelhante entre os materiais testados, não houve diferença na utilização das camas.
Tabela 1. Média do tempo (minutos) despendido em cada atividade, para cada período

\begin{tabular}{ccrr}
\hline \multirow{2}{*}{ Período } & \multirow{2}{*}{ Atividade } & \multicolumn{2}{c}{ Cama } \\
\cline { 3 - 4 } Madrugada & Areia & Borracha \\
& DO & $50: 43(2,30) \mathrm{a}$ & $51: 31(3,14) \mathrm{a}$ \\
& DR & $43: 29(2,48) \mathrm{a}$ & $41: 21(4,10) \mathrm{a}$ \\
& E0 & $10: 34(1,07) \mathrm{a}$ & $11: 16(1,33) \mathrm{a}$ \\
Manhã & ER & $24: 36(2,31) \mathrm{a}$ & $21: 21(2,05) \mathrm{a}$ \\
\hline \multirow{5}{*}{ Tarde } & D0 & $43: 10(3,21) \mathrm{a}$ & $29: 03(2,53) \mathrm{b}$ \\
& DR & $45: 52(3,16) \mathrm{a}$ & $34: 55(2,37) \mathrm{b}$ \\
& EO & $9: 55(1,17) \mathrm{a}$ & $12: 13(1,13) \mathrm{a}$ \\
& ER & $8: 20(1,27) \mathrm{a}$ & $11: 54(1,14) \mathrm{a}$ \\
\hline \multirow{4}{*}{ Noite } & DO & $32: 32(1,53) \mathrm{a}$ & $30: 10(4,17) \mathrm{b}$ \\
& DR & $46: 31(3,10) \mathrm{a}$ & $37: 37(3,19) \mathrm{b}$ \\
& EO & $8: 20(0,54) \mathrm{a}$ & $8: 49(1,24) \mathrm{b}$ \\
& ER & $17: 37(1,22) \mathrm{a}$ & $18: 10(1,40) \mathrm{b}$ \\
\hline & D0 & $27: 37(1,49) \mathrm{a}$ & $18: 15(1,00) \mathrm{a}$ \\
& DR & $33: 58(3,27) \mathrm{a}$ & $18: 05(2,26) \mathrm{b}$ \\
& EO & $5: 43(0,51) \mathrm{a}$ & $11: 02(1,15) \mathrm{a}$ \\
& ER & $5: 33(1,01) \mathrm{a}$ & $12: 04(1,02) \mathrm{a}$ \\
\hline
\end{tabular}

DO - deitada em ócio, DR - deitada ruminando, EO - em pé ócio, ER - em pé ruminando Médias seguidas de mesma letra na linha são estatisticamente iguais, pelo teste de $\mathrm{F}(\mathrm{P}<0,05)$

Do tempo total de observação elas permaneceram $22 \%$ deitadas na cama de areia e $25 \%$ no colchão de borracha e nesta posição o tempo em ócio (50 min e 43 s, e 51 min e 31 s), apresentou tendência de ser maior do que o tempo ruminando (43 min e 29 s e 41 min e 21 s) nas camas de areia e borracha, respectivamente (Tabela 1). Comportamento semelhante foi observado por Damasceno et al. (1999) que, trabalhando com camas de areia em free-stall, observaram preferência dos animais em ruminar deitados, principalmente nos períodos fora das horas mais quentes do dia passando a ruminar mais tempo em pé durante períodos quentes devido ao estresse pelo calor. No presente estudo ficou evidenciado que a cama de areia proporciona maior conforto às vacas. Esta constatação pode ser corroborada pela assertiva de Haley et al. (2001) que afirmam que que o tempo total gasto deitadas e repousando pode ser usado como parâmetro para avaliação do conforto para as vacas.

A preferência pela cama de areia identificada neste trabalho pode estar relacionada também com a sanidade dos cascos já que estudos de Cook (2003), Espejo et al. (2006) e Norring et al. (2008), sugerem que há maior preferência pelas vacas em usar baias com cama de areia, uma vez que este material provoca menor incômodo nos cascos. Fregonesi et al. (2007) relatam que camas permanentemente secas demonstraram características semelhantes às de lugares mais conhecidos pelos animais para se deitarem, como pastagens ou campos. Mencionada semelhança também pode ter favorecido o uso da cama de areia.

Os resultados obtidos neste trabalho se opõem àqueles relatados por Mitev et al. (2012) que, comparando três tipos de cama, tapete de borracha (semelhante a um dos tratamentos empregados neste trabalho, esterco e palha), observaram preferência por baias com tapetes de borracha. Do mesmo modo, Norring et al. (2010) relatam, comparando camas recobertas com areia, tapetes de borracha e concreto em temperaturas que variavam de -20 a $8{ }^{\circ} \mathrm{C}$ dentro da instalação, que o tempo de repouso foi maior nas baias com tapetes de borracha cujos 
dados podem indicar que em locais de temperaturas baixas o material composto por borracha pode ser mais confortável aos animais. Em experimento realizado no Canadá, Rushen et al. (2007) observaram que as vacas tendem a descansar mais em tapete de borracha do que em baias com a base de concreto com adição de $0,5 \mathrm{~kg}$ de palha por baia, em instalações tipo tie-stall.

O tempo de permanência ER (em pé ruminando sobre a cama) e EO (em pé ócio sobre a cama) na areia (25 min e 57 s) e no colchão de borracha (26 min e 59 s) só diferiu estatisticamente no período da tarde (Tabela 1), período este em que os valores de ITGU estavam mais elevados em comparação com os demais períodos (Figura 2).

O comportamento de ruminar com duas patas na cama está ligado à sensação de desconforto animal, segundo Potter \& Broom (1986) o que demonstra, neste estudo, a cama de borracha não estava agradável o suficiente para os animais permanecerem deitados no período da tarde.
As temperaturas registradas na superfície da cama de borracha foram altas neste período o que, provavelmente, gerou desconforto aos animais os quais, por sua vez, optavam por permanecer em pé com as patas sobre a cama.

\section{Temperatura das camas}

À tarde, a temperatura média da cama de borracha foi mais elevada que aquela observada na cama de areia $(\mathrm{P}<0,05)$ (Tabela 2); já no período da madrugada se observa o contrário, isto é, a cama de areia apresentou temperatura média mais alta.

Em dias de temperaturas mais altas as camas apresentaram temperaturas superficiais elevadas devido, provavelmente, à incidência de radiação direta e indireta sobre o material. No dia em que se observou o maior valor absoluto de ITGU (76,4 para areia e 81,9 para borracha), valores acima do índice de conforto estabelecido por National Weather Service (EUA), segundo Baêta \& Souza (2010), ocorreram também os maiores
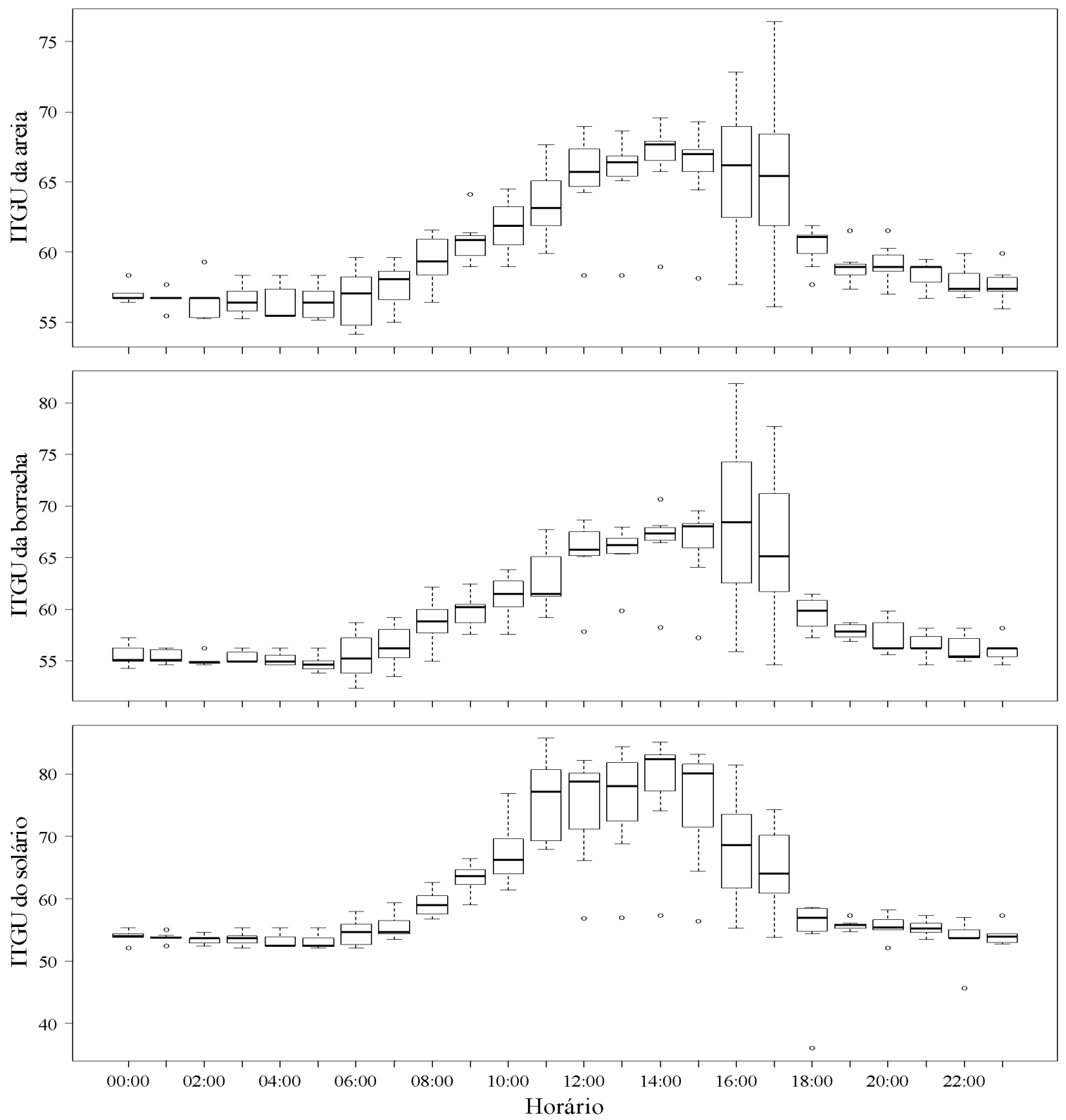

Figura 2. Valores de Índice de Temperatura de Globo e Umidade (ITGU) nas camas de areia, de borracha e no solário 
Tabela 2. Valores médios da temperatura $\left({ }^{\circ} \mathrm{C}\right)$ das camas de areia e borracha, para cada período

\begin{tabular}{lcc}
\hline Período & \multicolumn{2}{c}{ Cama } \\
\cline { 2 - 3 } Madrugada & Areia & Borracha \\
Manhã & $24,11 \mathrm{a}$ & $22,91 \mathrm{~b}$ \\
Tarde & $25,88 \mathrm{a}$ & $26,17 \mathrm{a}$ \\
Noite & $30,83 \mathrm{a}$ & $32,28 \mathrm{~b}$ \\
& $24,80 \mathrm{a}$ & $24,94 \mathrm{a}$ \\
\hline
\end{tabular}

Médias seguidas de mesma letra na linha são estatisticamente iguais, pelo $\mathrm{F}$ a 0,05

valores de temperatura superficial das camas, ou seja, $46,6^{\circ} \mathrm{C}$ para cama de areia e $52{ }^{\circ} \mathrm{C}$ para cama de borracha valores que ocorreram entre $15 \mathrm{e} 16 \mathrm{~h}$.

A elevação da temperatura média das camas acompanhou o aumento da temperatura do ar ambiente atingindo valores máximos entre 15 e $16 \mathrm{~h}$ (Figura 3 ). A temperatura elevada à tarde fez com que os animais evitassem deitar ou aqueles que estivessem deitados permanecerem nesta atividade, em camas de material composto de borracha.
Pesquisas anteriores já haviam determinado que a temperatura ambiente circundante dentro de instalações freestall afeta o comportamento das vacas. Wagner-Storch et al. (2003) observaram que a temperatura ambiente influencia diretamente no tempo gasto em cada comportamento deitado em baias recobertas com diferentes materiais.

Thoreson et al. (2000) relataram que durante o verão a taxa de ocupação em camas de areia foi maior em comparação com a de colchões e esteiras de borrachas. Os mesmos autores concluíram que a taxa de ocupação das baias com cama de areia foi menor nos meses de inverno do que nos meses de verão. Wagner-Storch et al. (2003), avaliando os seguintes materiais: colchão de borracha, colchão de água, tapete de borracha, concreto e areia, afirmam que a utilização das baias diminuiu à medida em que a temperatura ambiente aumentou. As vacas preferiram deitar sobre camas de areia em instalações freestall quando as temperaturas estiveram entre -6 e $15^{\circ} \mathrm{C}$. Em
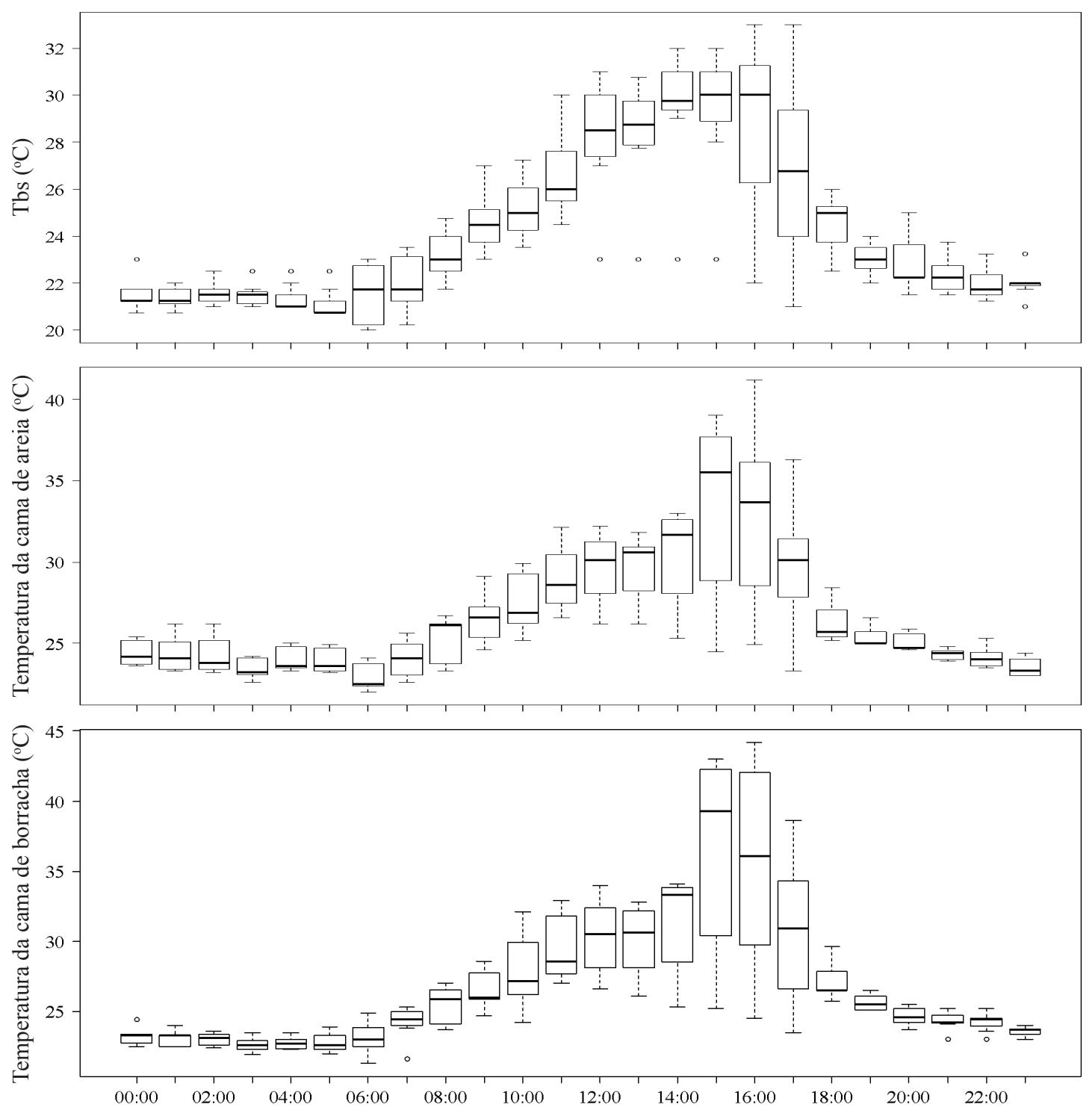

Horário

Figura 3. Temperatura de bulbo seco (Tbs) no interior da instalação, Temperatura da cama de areia e de borracha observadas em diferentes horários 
temperaturas mais baixas $\left(-17\right.$ a $\left.-6^{\circ} \mathrm{C}\right)$ a taxa de ocupação em colchão de água foi maior em comparação com a de tapete de borracha e concreto mas quando a temperatura era mais alta (27 a $38^{\circ} \mathrm{C}$ ) foi observada redução nessa taxa de ocupação.

De forma semelhante ao constatado no presente estudo, Cook et al. (2007) depreenderam que o gado leiteiro passa menos tempo deitado em baias quando a temperatura ambiente está elevada. Silva et al. (2010) esclarecem que o ambiente é considerado ideal quando o animal está em equilíbrio térmico. Percebeu-se, no presente trabalho, que em temperaturas mais elevadas os animais evitam elevar sua temperatura corporal pela absorção de calor por condução advinda do material de cama.

Constatou-se que a capacidade do material utilizado nas camas em dissipar ou absorver pode afetar a decisão do bovino em se deitar na baia. Camerini \& Nascimento (2012) corroboram que, para reduzir a transferência de calor de um corpo para o outro, é necessário que o material não seja bom condutor térmico.

\section{Conclusões}

1. Constata-se que houve maior utilização da cama de areia mas com pequena diferença em relação ao colchão de borracha sugerindo que este tempo provavelmente não implica em desconforto dos animais, estresse nem na redução da produção de leite.

2. Observou-se que a temperatura ambiente interfere diretamente na temperatura das camas principalmente de borracha o que influencia, sobremaneira, o comportamento dos animais.

\section{Agradecimentos}

À Empresa Brasileira de Pesquisa Agropecuária - EMBRAPA Gado de Leite, pela disponibilidade de desenvolvimento do experimento; à Coordenação de Aperfeiçoamento de Pessoal de Nível Superior (CAPES), pela concessão da bolsa de estudo e à empresa SANSUY, pelo fornecimento do material de cama empregado no presente estudo.

\section{Literatura Citada}

Baêta, F. C.; Souza, C. F. Ambiência em edificações rurais: Conforto animal. 2.ed. Viçosa: UFV, 2010. 269p.

Bond, G. B.; Almeida, R.; Ostrensky, A.; Molento, C. F. M. Métodos de diagnóstico e pontos críticos de bem-estar de bovinos leiteiros. Ciência Rural, v.42, p.1286-1293, 2012.

Boone, R. E. Comparison of freestall bedding materials and their effect on cow behavior and cow health. Florida: University of Florida. 2009. 100p. Thesis Master

Buffington, D. E.; Collazo-Arocho, A.; Canton, G. H. Pitt, D. Black globe humidity index (BGHI) as a comfort equation for dairy cows. Transactions ASAE, v.24, p.711-714, 1981.
Camerini, N. L.; Nascimento, J. W. B. do. Análise da influência do revestimento de resíduo de EVA no conforto térmico de instalações agropecuárias. Revista Eletrônica de Materiais e Processos, v.7, p.48-51, 2012.

Castro, J. O.; Campos, A. T.; Ferreira, R. A.; Yanagi Júnior, T.; Tadeu, H. C. Uso de ardósia na construção de celas de maternidade: I - efeito sobre o ambiente e comportamento de suínos. Engenharia Agrícola, v.31, p.458-467, 2011.

Cook, N. B. Prevalence of lameness among dairy cattle in Wisconsin as a function of housing type and stall surface. Journal of the American Veterinary Medical Association, v.223, p.1324-1328, 2003.

Cook, N. B.; Mentink, R. L.; Bennett, T. B. E.; Burgi, K. The effect of heat stress and lameness on time budgets of lactating dairy cows. Journal of Dairy Science, v.90, p.1674-1682, 2007.

Damasceno, J. C.; Baccari Júnior, F. E.; Targa, L. A. Respostas comportamentais de vacas holandesas, com acesso à sombra constante ou limitada. Pesquisa Agropecuária Brasileira, v.34, p.709-15, 1999.

Espejo, L. A.; Endres, M. I.; Salfer, J. A. Prevalence of lameness in high-producing Holstein cows housed in freestall barns in Minnesota. Journal of Dairy Science, v.89, p.3052-3058. 2006.

Fisher, A. D.; Verkerk, G. A.; Morrow, C. J.; Matthews, L. R. The effects of feed restriction and lying deprivation on pituitary-adrenal axis regulation in lactating cows. Livestock Production Science, v.73, p.255-63, 2002.

Fregonesi, J. A.; Veira, D. M.; Keyserlingk, M. A. G. von; Weary, D. M. Effects of bedding quality on lying behavior of dairy cows. Journal of Dairy Science, v.90, p.5468-5472, 2007.

Haley, D.; Passile, A. M. de; Rushen, J. Assessing cow comfort: Effects of two floor types and two tie stall designs on the behavior of lactating dairy cows. Applied Animal Behaviour Science, v.71, p.105-117, 2001.

Haussmann, M. F.; Vleck, C. M.; Farrar, E. S. A laboratory exercise to illustrate increased salivary cortisol in response to three stressful conditions using competitive ELISA. Advances in Physiology Education. v.31, p.110-115, 2007.

Herlin, A. Comparison of lying area surfaces for dairy cows by preference, hygiene and lying down behaviour. Swedish Journal of Agricultural Research, v.27, p.189-96, 1997.

Mitev, J; Varlyakov, I; Miteva, T.; Vasilev, N.; Gergovska, J.; Uzunova, K.; Dimova, V. Preferences of freestall housed dairy cows to different bedding materials. Journal of the Faculty of Veterinary Medicine Istanbul University, v.38, p.135-140, 2012.

Munksgaard, L.; Jensen, M. B.; Pedersen, L. J.; Hansen, S. T.; Matthews, L. Quantifying behavioural priorities - Effects of time constraints on behaviour of dairy cows, Bos taurus. Applied Animal Behaviour Science, v.92, p.3-14, 2005.

Nielsen, B. L.; Veerkamp, R. F.; Lawrence, A. B. Effects of genotype, feed type and lactational stage on the time budget of dairy cows. Acta Agriculture Scandinavica, Section A, Animal Science, v.50, p.272-278, 2000. 
Norring, M.; Manninen, E.; Passille, A. M.; Rushen, J.; Munksgaard, L.; Saloniemi, H. Effects of sand and straw bedding on the lying behavior, cleanliness, and hoof and hock injuries of dairy cows. Journal of Dairy Science, v.91, p.570-576, 2008.

Norring, M.; Manninen, E.; Passille, A. M.; Rushen, J.; Saloniemi, $\mathrm{H}$. Preferences of dairy cows for three stall surface materials with small amounts of bedding. Journal of Dairy Science, v.93, p.70-74, 2010.

Perissinotto, M.; Moura, D. J.; Cruz, V. F.; Souza, S. R. L. de; Lima, K. A. O. de; Mendes, A. S. Conforto térmico de bovinos leiteiros confinados em clima subtropical e mediterrâneo pela análise de parâmetros fisiológicos utilizando a teoria dos conjuntos fuzzy. Ciencia Rural, v.39, p.1492-1498, 2009.

Potter, M. J.; Broom, D. M. Behaviour and welfare of cows in a cubicle house. The behaviour and welfare of cows in relation to cubicle house design. In: Wierenga, H. K, Peterse, D. J. Cattle Housing Systems: lameness and behaviour. Boston: Martinus Nijhoff Publishers, 1986. p.159-165.

Rushen, J.; Haley, D.; Passillé, A. M. de. Effect of softer flooring in tie stalls on resting behavior and leg injuries of lactating cows. Journal of Dairy Science, v.90, p.3647-3651, 2007.
Silva, E. V. C. E; Katayama, K. A.; Mace, G. G.; Rueda, P. M.; Abreu, U. G. P.; Ari, C. E. S. N. Z. Efeito do manejo e de variáveis bioclimáticas sobre a taxa de gestação em vacas receptoras de embriões. Ciência Animal Brasileira, v.11, p.280-291, 2010.

Silva, R. G. Introdução à bioclimatologia animal. São Paulo: Nobel, 2000. 286p.

Souza, B. B.; Silva, R. M. N.; Marinho, M. L.; Silva, G. A.; Silva, E. M. N. da; Souza, A. P. Parâmetros fisiológicos e índice de tolerância ao calor de bovinos da raça Sindi no semi-árido paraibano. Ciência e Agrotecnologia, v.31, p.883-88, 2007.

Thoreson, D. R.; Lay, D. C.; Timms, L. L. Dairy free stall preference field study. Dairy Report. Ames: Iowa State University. 2000. 5p.

Wagner-Storch, A. M.; Palmer, R. W.; Kammel, D. W. Factors affecting stall use for different free stall bases. Journal of Dairy Science, v.86, p.2253-2266, 2003.

Zdanowicz, M.; Shelford, J. A.; Tucker, C. B.; Weary, D. M.; Von Keyserlingk, M. A. G. Bacterial populations on teat ands of dairy cows housed in free stalls and bedded with either sand or sawdust. Journal of Dairy Science, v.87, p.16941701, 2004. 